\title{
The Influence of Structural Monetary Policy on Bond Market
}

\author{
Pin Peng \\ School of Finance, Zhongnan University of Economics and Law, Wuhan, 430073, China
}

Keywords: Structural monetary policy, Bond market, Macro economy

\begin{abstract}
Structural monetary policy is different from the traditional monetary policy tools, which has a directional role in regulating China's economic operation. This paper chooses the indicators representing the liquidity of the bond market and monetary policy, combines the yield and volatility of the bond market as the control variables, and uses the VAR model to make an empirical study on the impact of structural monetary policy on the liquidity of the bond market. The results show that structural monetary policy has a relatively poor impact on the bond market. On this basis, this paper puts forward corresponding countermeasures and suggestions to provide some references for the relevant researchers.
\end{abstract}

\section{Introduction}

Structural monetary policy, as an important monetary policy innovation to supplement market liquidity and actively regulate the economy, has an important impact on the bond market. A thorough study of the impact mechanism will help policy makers and market investors to accurately assess the extent of the impact on the bond market. After 2013, structural monetary policy instruments such as short-term liquidity adjustment tools, standing lending facilities, medium-term lending facilities and mortgage supplementary loans were introduced. These structural monetary policy instruments complement the traditional monetary policy instruments such as open market operation, deposit reserve ratio and interest rate, and jointly regulate the monetary market and bond market, thereby affecting macro-economy. The important macroeconomic background of launching structural monetary policy tools is the change of the balance of payments pattern. From a double surplus to a one-way surplus, the foreign exchange share has rapidly declined, and the central bank needs new monetary policy tools to replenish liquidity. In the context of the double surplus, RMB appreciation took place and foreign exchange accounts have increased rapidly, excess liquidity. The central bank has to hedge operations. However, as China's economy entered a new normal, the Federal Reserve opened the channel for interest rate hikes, and international capital inflows turned, resulting in a rapid decline in foreign exchange. Medium-term lending facilities play the role of medium-term policy interest rates, adjusting the medium-term financing costs of financial institutions and their lending rates, usually for a period of three months, six months or one year. Compared with traditional monetary policy instruments, structural monetary policy instruments have obvious characteristics. Structural monetary policy instruments are more flexible, which play a role in regulating market liquidity, and avoid excessive market volatility.

\section{Empirical Research on Influence of Structural Monetary Policy on Bond Market}

\subsection{Select Variables}

The liquidity of bond market is measured by turnover rate. Although the inter-bank bond market is the main body of China's bond market at present, it is very difficult to collate and collect basic data because of its imperfect market maker system. Previous studies have also shown that the weakening of liquidity in the bond market of the Shanghai Stock Exchange has not resulted in the improvement of liquidity in the inter-bank market. The liquidity breadth and elasticity index of the Shanghai Stock Exchange is still better than that of the inter-bank market to a certain extent, and the Shanghai Stock 
Exchange market fully reveals Trading information, providing the most powerful support for price discovery, and ultimately taking shape. The transaction data is more stable. Therefore, this paper finally uses the SSE Treasury bond index turnover profile to calculate the monthly turnover rate, with the SSE Treasury bond component stocks monthly turnover amount than the component stocks at the end of the month circulation market value, the greater the turnover rate, the better the market liquidity. The central bank's monetary policy operation is mainly realized by money supply and interest rate. Therefore, this paper uses the monthly mean of money supply (M2) and seven-day interbank lending rate $(\mathrm{R})$ as monetary policy indicators. In addition to directly affecting the liquidity of the securities market, monetary policy also affects the market liquidity by affecting market returns, volatility and other aspects. Therefore, this paper also uses the Shanghai Composite Index monthly rate of return (RB) as an indicator. The sample time span of this study is from January 2009 to December 2017, using monthly data. Table 1 is the result of each variable description statistics.

Table 1 Statistical result of the selected variables

\begin{tabular}{|c|c|c|c|c|c|}
\hline & LB & LS & M2 & R & RB \\
\hline Mean & 2.8596 & 103.252 & 435858 & 0.0215 & 0.0028 \\
\hline Median & 0.9364 & 74.894 & 356242 & 0.0216 & 0.0028 \\
\hline Maximum & 21.451 & 402.263 & 856984 & 0.0456 & 0.0028 \\
\hline Minimum & 0.1021 & 11.527 & 194787 & 0.0084 & -0.0621 \\
\hline $\begin{array}{c}\text { Standard } \\
\text { deviation }\end{array}$ & 3.6664 & 90.555 & 195242 & 0.0074 & 0.0098 \\
\hline Skewness & 2.854 & 1.269 & 0.584 & 0.3645 & -2.3382 \\
\hline Kurtosis & 7.784 & 4.015 & 2.012 & 3.6541 & 3.951 \\
\hline JB test & 184.232 & 36.632 & 10.236 & 10.871 & 4.258 \\
\hline
\end{tabular}

\subsection{Establish VAR Model}

To avoid the pseudo-regression phenomenon, the stationarity test of each variable is carried out. The test results show that the money supply is not stable at the $10 \%$ significance level, DM2 is stable at the $10 \%$ significance level, and the other variables are also stable. Because of the time lag effect widely existing in economic activities, some economic variables are not only affected by synchronous factors, but also may be affected by various factors in some past periods or even their own past values. Therefore, this paper adopts the VAR model which is currently the mainstream in the empirical test. There is a significant lead-lag relationship between the liquidity of the stock market and the bond market in China, and it is also a cause-effect relationship between them. Similarly, we should take into account the impact of stock market liquidity when establishing VAR models in the bond market. At the 5\% significance level, money supply is the Granger cause of the liquidity index of the stock market, the liquidity of the stock market is the Granger cause of the interbank lending rate, and the other causality is not significant. Granger test is only to test whether the lag value of each variable has a significant impact on the current period, does not mean that there is a real causal relationship, so the next use of impulse response function analysis. Impulse response function is used to describe the response trajectories of specific variables to other variables. Specifically, the impact of a standard deviation on the current and future values of the endogenous variables is observed on the basis of a random error term.

\subsection{Present Results}

We give the money supply a positive impact, the bond market liquidity will weaken and then gradually stabilize; the interbank lending rate increases will lead to the bond market liquidity enhancement; the spillover effect between the stock market and the bond market is negative correlation effect. The stock market liquidity increases, the bond market liquidity weakens. Bond market returns and volatility also have a significant impact on the liquidity of the bond market. The largest contribution of money supply to the forecasting error of bond market liquidity is $4.41 \%$. The 
liquidity of bond market is also affected by its own yield and volatility.

Table 2 Variance decomposition of bond market liquidity

\begin{tabular}{|c|c|c|c|c|c|}
\hline Period & LB & LS & M2 & R & RB \\
\hline 1 & 100.000 & 0.000 & 0.000 & 0.000 & 0.000 \\
\hline 3 & 95.118 & 0.802 & 0.547 & 1.824 & 1.554 \\
\hline 5 & 91.405 & 0.773 & 0.978 & 2.215 & 2.974 \\
\hline 7 & 82.268 & 1.856 & 0.412 & 3.222 & 3.070 \\
\hline 9 & 81.260 & 1.439 & 0.662 & 4.511 & 4.790 \\
\hline 11 & 76.131 & 1.971 & 0.845 & 5.775 & 4.915 \\
\hline 13 & 74.618 & 2.926 & 1.647 & 6.538 & 4.892 \\
\hline 15 & 72.360 & 2.124 & 1.058 & 7.254 & 4.528 \\
\hline 17 & 71.477 & 3.067 & 1.866 & 8.153 & 4.349 \\
\hline 19 & 70.690 & 4.411 & 1.523 & 9.659 & 4.063 \\
\hline
\end{tabular}

\section{Results Analysis of Empirical Research and Policy Recommendations}

\subsection{Optimize Term Structure of Bonds}

The long-term high savings rate proves that reserve funds are never scarce for China's securities market. The key is whether the bond market can give investors the expected return. In the current situation of limited investment channels, investors will naturally withdraw funds from the bond market and deposit them in banks, even if there is macro-control it is difficult to prevent funds from entering the bond market. The term structure here mainly refers to the proportion of long-term, short-term, medium-term bonds of different maturity types in government bonds. At present, there are some problems in the term structure of government bonds in China, such as: the types of transaction of various maturities are not rich and varied, the types are monotonous, mainly in the medium and long term bonds, and the types and quantities of short-term bonds are few. This guarantees the size of government bonds, but reduces their liquidity, making it difficult to meet the demand for short-term investors. We should expand the number of short-term bonds issued at the same time, increase the proportion of short-term bonds in the term structure, and issue them on a rolling basis, to make different maturity types. It can match and complement each other reasonably and distribute in a balanced way, which can not only meet the demand of the government for different long-term and short-term funds, but also meet the demand preference of different types of investors; secondly, it is necessary to construct a reasonable information disclosure system to give information about the issuance time, amount and type of the next bond through various information channels. The issuance will enable investors to grasp the investment information in advance and fully prepare for the corresponding funds, and reduce the uncertainty of government bond issuance.

\subsection{Develop Credit Bonds}

The results of impulse response function show that the positive impact of bond market on money supply shows that liquidity weakens and then tends to be stable, and the response of stock market is much larger than that of bond market, which can also be seen from the result of variance decomposition. While the interbank offered rate increased, the liquidity of the bond market increased. The inconsistency of the main structure of issuing credit bonds not only makes it difficult for monetary policy to play a normal and effective transmission role in the bond market, but also makes its impact areas greatly reduced. Therefore, credit bonds should be actively promoted to provide direct financing services to the real economic sector, to streamline the monetary policy transmission process and links to make the transmission process more smooth and unimpeded. The future development potential of China's credit bond market can not be underestimated, should become the 
focus of current development, enterprises should also become the main force in the bond market. The inconsistency of the main structure of issuing credit bonds not only makes it difficult for monetary policy to play a normal and effective transmission role in the bond market, but also makes its impact areas greatly reduced. Therefore, credit bonds should be actively promoted to provide direct financing services to the real economic sector to streamline the monetary policy transmission process and links to make the transmission process more smooth and unimpeded. The future development potential of China's credit bond market can not be underestimated, should become the focus of current development, enterprises should also become the main force in the bond market. The inconsistency of the main structure of issuing credit bonds not only makes it difficult for monetary policy to play a normal and effective transmission role in the bond market, but also makes its impact areas greatly reduced. Therefore, credit bonds should be actively promoted to provide direct financing services to the real economic sector to streamline the monetary policy transmission process and links, to make the transmission process more smooth and unimpeded. The future development potential of China's credit bond market can not be underestimated, should become the focus of current development, enterprises should also become the main force in the bond market.

\subsection{Reduce Transaction Costs in Bond Market}

Through the establishment of competition and incentive mechanism, bond intermediaries and settlement departments can improve service attitude, improve service quality and reduce service prices, the formation of a benign competitive atmosphere. When choosing the mode of transaction, we should try our best to choose a simple and low-cost trading mode, which can save unnecessary intermediate operation process, save time for both sides, and reduce the handling fee, so that investors are more willing to accept. For example, remote transactions and electronic settlement are all low cost and low cost transactions. For the trading of specific bond types, the relevant regulatory authorities may give certain preferential policies and implement preferential tax measures. We can formulate certain tax relief policies according to the risk of issuing bonds and the situation of bond issuing enterprises, which can not only support immature emerging industries, but also reduce the transaction cost burden of investors. In addition to commercial banks, credit cooperatives, securities companies, insurance companies, fund companies and other non-bank financial institutions have been introduced into China's inter-bank bond market in recent years. The types of investors are increasing day by day, but individual investors and ordinary legal persons cannot participate in the inter-bank bond market. They can only buy fund products or other non-bank financial institutions. Financial products of banks and securities companies are indirectly involved. To realize the unification of the bond market, we should first of all relax the restrictions on the participation of the trading subjects in the bond market, allow all kinds of investors to enter and exit freely among the trading markets according to their own needs, and promote the unification of the bond market through the interconnection of the participants. China's market maker system is not yet mature. According to the actual situation of market makers, we constantly adjust and improve the market making rules.

\section{Conclusion}

Structural monetary policy can replenish the problem of insufficient liquidity in the bond market and stabilize credit spreads. Of course, the direction in which structured monetary policy affects credit spreads also depends on the stage of the economic cycle. For example, in the boom period, the market investment enthusiasm is better and investors have a higher risk preference. They will choose to invest more high-yield, high-risk corporate bonds and credit spreads will narrow. This is the point where we need to pay attention to structural monetary policy.

\section{References}

[1] Lu Lan, Deng Xiong. International Comparison of Structural Monetary Policy Tools and Inspiration [J]. World Economy Studies, 2015(6): 3-11+127.

[2] Liu Gang, Chen Xu. The Influence Mechanism of Structural Monetary Policy on Bond Market [J]. 
The Chinese Banker, 2017(12): 106-107.

[3] Zheng Lei. Analys is of the Transmission of Monetary Policy in the Bond Market [J]. Financial Development Review, 2016(5): 83-90.

[4] Zhang Yuan. A Study on the Further Improvement of China's Structural Monetary Policy [J]. Price: Theory \& Practice, 2016(1): 122-125. 